\title{
Aspirin and risk of different cancers: an umbrella meta-analysis
}

\author{
Yu Jiang ${ }^{1,2,3,4,5}$, Zixuan Su ${ }^{1,2,3,4,5}$, Runchen Wang ${ }^{1,2,3,4,5}$, Fan Ge ${ }^{1,2,3,4,5}$, Zhenyu Huo ${ }^{1,2,3,4,5}$, Yaokai Wen ${ }^{1,2,3,4,5}$, \\ Caichen Li ${ }^{1,2,3,4}$, Hengrui Liang ${ }^{1,2,3,4}$, Jianxing $\mathrm{He}^{1,2,3,4}$, Wenhua Liang ${ }^{1,2,3,4}$
}

\begin{abstract}
${ }^{1}$ Department of Thoracic Surgery and Oncology, the First Affiliated Hospital of Guangzhou Medical University, Guangzhou, China; ${ }^{2}$ State Key Laboratory of Respiratory Disease, Guangzhou, China; ${ }^{3}$ National Clinical Research Center for Respiratory Disease, Guangzhou, China; ${ }^{4}$ Guangzhou Institute of Respiratory Health, Guangzhou, China; ${ }^{5}$ Nanshan School, Guangzhou Medical University, Guangzhou, China

Correspondence to: Wenhua Liang, MD; Jianxing He, MD, PhD, FACS, FRCS, AATS active member, ESTS member. Department of Thoracic Oncology, the First Affiliated Hospital of Guangzhou Medical University; China State Key Laboratory of Respiratory Disease \& National Clinical Research Center for Respiratory Disease, Guangzhou, China. Email: liangwh1987@163.com; drjianxing.he@gmail.com.
\end{abstract}

Submitted Aug 01, 2020. Accepted for publication Sep 06, 2020.

doi: $10.21037 /$ atm-20-5627

View this article at: http://dx.doi.org/10.21037/atm-20-5627

We have read with great interest the article "Aspirin use and endometrial cancer risk: a meta-analysis and systematic review" by Wang et al. (1) Growing evidences have been reported on the protective effect of aspirin on multiple types of cancers, but the determinants of clinical benefit remain elusive. Tumor mutational burden (TMB) is an emerging and independent biomarker to evaluate the effect of immunotherapy. And tumors with defects in mismatch repair (MMR) may lead to microsatellite instability (MSI) and such increased mutational burden in tumors result in higher sensitivity to immune response $(2,3)$. In this study, we combined the data from 224 cohort studies and correlated the effects of aspirin on cancer prevention with TMB or MMR/MSI.

Eligible studies were identified by searching the PubMed, Medline, EMBASE, and Cochrane Library databases up to May 2020. Only cohort studies, nested casecontrol studies and randomized controlled trials (RCTs) investigating regular aspirin use and different cancers risks were included. Fixed-effects models were used to calculate the pooled relative risks (RRs) and their $95 \%$ confidence intervals (CIs). In addition, the linear regression weighted by sample size were performed to analyze the relationship between the RRs and TMB, as well as MMR/MSI.

A total of 224 studies involving 44,833,614 participants were included. Compared to the general population, regular aspirin use was associated with a modest reduction of overall cancer risk $(\mathrm{RR}=0.90 ; 95 \% \mathrm{CI}, 0.89-0.91$; $\mathrm{P}<0.001)$, as well as the risk of lung cancer $(\mathrm{RR}=0.87 ; 95 \%$ CI, 0.85-0.89; $\mathrm{P}<0.001)$, leukemia $(\mathrm{RR}=0.82 ; 95 \% \mathrm{CI}$, 0.73-0.93; $\mathrm{P}=0.001)$, colorectal cancer $(\mathrm{RR}=0.82 ; 95 \% \mathrm{CI}$, $0.81-0.84 ; \mathrm{P}<0.001)$, hepatobiliary cancer $(\mathrm{RR}=0.55 ; 95 \%$ CI, 0.51-0.59; $\mathrm{P}<0.001$ ), esophageal cancer $(\mathrm{RR}=0.71 ; 95 \%$ CI, 0.66-0.76; $\mathrm{P}<0.001)$ and gastric cancer $(\mathrm{RR}=0.83 ; 95 \%$ CI, 0.80-0.86; $\mathrm{P}<0.001)$. However, there were no significant associations of aspirin use with other cancers, including cancers of head and neck, breast, cervical uterus, kidney, bladder, thyroid, skin, as well as lymphoma. As shown in Figure 1, the scatterplots illustrated the relationships between aspirin use and TMB, as well as MMR/MSI. The linear correlation coefficients were $0.53\left(\mathrm{R}^{2}=0.01, \mathrm{P}=0.650\right)$ and $-12.69\left(\mathrm{R}^{2}=0.26, \mathrm{P}=0.037\right)$ for TMBs (Figure $\left.1 A\right)$ and MMR/MSI (Figure $1 B$ ), suggesting that $1 \%$ and $26 \%$ of the variations in the RRs among different cancer types might be explained by the TMBs and MMR/MSI, respectively.

To our knowledge, no studies have elucidated the determinative factors in clinical benefit of aspirin use and this is the first study to focus on this issue. This most up-to-date population-level analysis supported the inverse associations between aspirin use and the risk of certain cancer types. Although our findings manifested the chemoprevention value of aspirin, it still needs to be interpreted with caution and it is inappropriate to promote aspirin as a universal chemoprotective agent for

$\wedge$ ORCID: 0000-0001-7344-7274. 

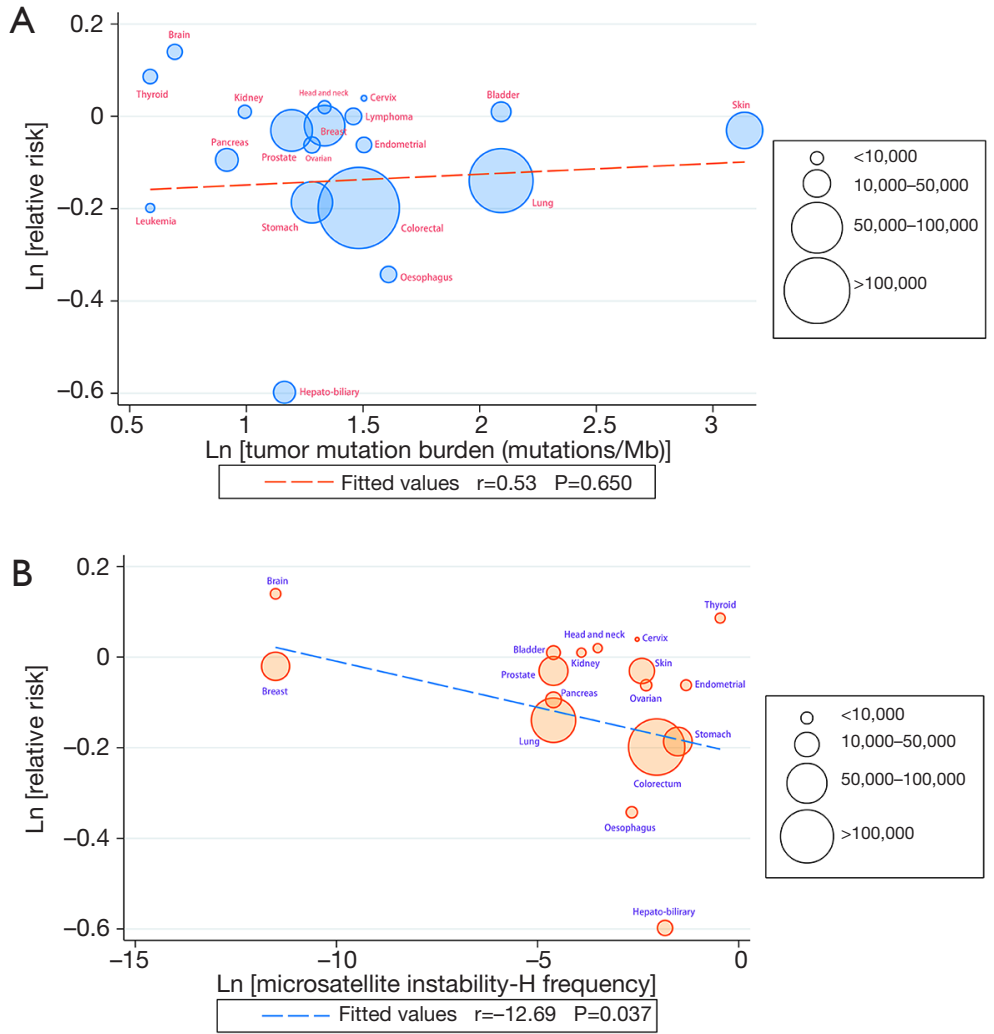

Figure 1 Correlation between RRs and TMBs in regular aspirin recipients are shown in (A). Correlation between RRs and MMR/MSI in regular aspirin recipients are shown in (B). RR, relative risk; TMB, tumor mutational burden; MMR, mismatch repair; MSI, microsatellite instability.

cancers. We found that greater cancer prevention effect of aspirin was statistically correlated to increased MMR/ MSI, suggesting that aspirin had diverse protective effects on different cancers, which may be attributed to various degrees of immunogenicity among different cancer types. With the continuous improvements in genetic and molecular biomarkers (4), future studies should attach more importance to identifying individuals with high risk for certain cancers, assessing the risk-benefit profile. In addition, these findings encouraged further studies to explore the correlation between aspirin and immune clearance/escape.

\section{Acknowledgments}

Funding: This work was supported by the National Key R\&D Program of China (2016YFC0905400); China National Science Foundation (81871893, 81501996); Key Project of Guangzhou Scientific Research Project
(201804020030); High-Level University Construction Project of Guangzhou Medical University (20182737, 201721007, 201715907, 2017160107); IVATS National Key R\&D Program (2017YFC0907903, 2017YFC0112704) and Application, Industrialization and Generalization of Surgical Incision Protector (2011B090400589).

\section{Footnote}

Provenance and Peer Review: This article was a free submission to the journal. The article did not undergo external peer review.

Conflicts of Interest: All authors have completed the ICMJE uniform disclosure form (available at http://dx.doi. org/10.21037/atm-20-5627). JH serves as an unpaid Editorin-Chief of Annals of Translational Medicine from June 2019 to May 2024. The other authors have no conflicts of interest to declare. 
Ethical Statement: The authors are accountable for all aspects of the work in ensuring that questions related to the accuracy or integrity of any part of the work are appropriately investigated and resolved.

Open Access Statement: This is an Open Access article distributed in accordance with the Creative Commons Attribution-NonCommercial-NoDerivs 4.0 International License (CC BY-NC-ND 4.0), which permits the noncommercial replication and distribution of the article with the strict proviso that no changes or edits are made and the original work is properly cited (including links to both the formal publication through the relevant DOI and the license). See: https://creativecommons.org/licenses/by-nc-nd/4.0/.

Cite this article as: Jiang $\mathrm{Y}$, Su Z, Wang R, Ge F, Huo Z, Wen Y, Li C, Liang H, He J, Liang W. Aspirin and risk of different cancers: an umbrella meta-analysis. Ann Transl Med 2020;8(20):1333. doi: 10.21037/atm-20-5627

\section{References}

1. Wang Y, Zhao J, Chen X, et al. Aspirin use and endometrial cancer risk: a meta-analysis and systematic review. Ann Transl Med 2020;8:461.

2. Dudley JC, Lin MT, Le DT, et al. Microsatellite instability as a biomarker for PD-1 blockade. Clin Cancer Res 2016;22:813-20.

3. Snyder A, Makarov V, Merghoub T, et al. Genetic basis for clinical response to CTLA-4 blockade in melanoma. N Engl J Med 2014;371:2189-99.

4. Nan H, Hutter CM, Lin Y, et al. Association of aspirin and NSAID use with risk of colorectal cancer according to genetic variants. JAMA 2015;313:1133-42. 